\title{
PREDICTIVE VARIABLES OF ACUTE ALUMINUM PHOSPHIDE POISONING OUTCOME: A NEW PROPOSED MODEL
}

\author{
Mona M. Ghonem ${ }^{1}$, Sara I. El Sharkawy², Heba I. Lashin ${ }^{1}$ \\ ${ }^{1}$ Forensic Medicine and Clinical Toxicology Department, Faculty of Medicine, Tanta University, \\ Tanta, Egypt. \\ ${ }^{2}$ Cardiovascular Medicine Department, Faculty of Medicine, Tanta University, Tanta, Egypt. \\ Corresponding author: Mona M. Ghonem, Forensic Medicine and Clinical Toxicology \\ Department, Faculty of Medicine, Tanta University, Tanta, Egypt. \\ E-mail: mona.ghonaim@med.tanta.edu.eg \\ Telephone number: +201064257070
}

\begin{abstract}
Introduction: Acute aluminum phosphide (AlP) poisoning is a major toxicological challenge in developing countries especially in absence of specific antidote. Aim of the study: The current study aimed to identify predictive variables of outcome in acute AlP poisoning, then propose and validate a prediction model. Patients and Methods: This study was conducted on patients with acute AlP poisoning admitted at Tanta Poison Control Center from January 2018 to December 2018 (derivation group) and from January 2019 to June 2019 (validation group). For each patient, age, sex and toxicological characteristics were obtained. Clinical examination, routine laboratory investigations, central venous pressure measurement and electrocardiography were also done. Results: Data of the derivation group (110 patients) revealed that, systolic blood pressure, central venous pressure, $\mathrm{pH}$ and prothrombin time were significant predictive variables. Using univariate and multivariate regression analysis, systolic blood pressure, central venous pressure and $\mathrm{pH}$ were valid to construct the prediction model at cut off $\leq 85 \mathrm{mmHg},>22 \mathrm{cmH}_{2} \mathrm{O}$ and $\leq 7.33$ respectively. Variables were given points and the maximum sum points were 10 . The power of the proposed model to discriminate between survivors and non-survivors at cut off $\geq 4$ and $\geq 5$ sum points was excellent (AUC: 0.974 ). The discrimination power in the validation group (58 patients) was excellent (AUC: 0.917). Conclusion: This proposed model could be considered a simple and excellent tool to predict acute aluminum phosphide poisoning outcome.
\end{abstract}

KEYWORDS: Aluminum phosphide, poisoning, outcome, mortality, prediction model.

\section{ABBREVIATIONS}

AlP: Aluminum phosphide; GCS: Glasgow Coma Scale; ECG: Electrocardiogram CVP: Central venous pressure; QTc: corrected QT interval; ROC: receiver operating characteristic; AUC: Area under the curve; SBP: systolic blood pressure.

\section{INTRODUCTION}

Aluminium phosphide (AlP), also known as rice tablet, is an inorganic phosphide that is used as a fumigant to protect stored grains from insects, rodents and other pests (Yan et al., 2017). Due to its availability and low price, acute AlP 
poisoning constitutes one of the major causes of suicides especially among young adults in Egypt and many other developing countries (Sagah et al., 2015).

Acute AlP poisoning is mainly related to phosphine gas release when AlP is exposed to moisture or gastric acidity. Rapid absorption of phosphine gas through the gastrointestinal tract and lungs inhibits cytochrome-c oxidase enzyme and oxidative phosphorylation resulting in adenosine triphosphate depletion and then cell death occurs (Bansal et al., 2017).

Usually, very short duration is detected between AlP poisoning and the appearance of toxic manifestations (Goel and Aggarwal, 2007). Impaired myocardial contractility, fluid loss, pulmonary edema, metabolic acidosis and acute renal failure are reported to be the most frequent manifestations. However, disseminated intravascular coagulation and hepatic function impairment may also happen (Proudfoot, 2009). Multi-organ failure is generally encountered in nearly all deaths of acute AlP poisoning; meanwhile, myocardial damage is widely reported to be the primary mechanism of death (Soltani et al., 2016).

Acute AlP poisoning is a potentially fatal condition with no specific antidote and treatment is mainly supportive (Bansal et al., 2017). The incidence of poisoning is increasing steadily every year and it is important to predict the outcome of patients with acute AlP poisoning for appropriate patient setting and use of probable advanced procedures. In case of shortage of resources and their high cost, it is advisable to select patients who will get benefit from different resources and improve their outcome (Mashayekhian et al., 2016).

Glasgow Coma Scale (GCS), electrocardiogram (ECG), various laboratory markers and different scoring systems have been studied to predict mortality in acute AlP intoxicated patients; however results of their utility are still inconsistent (Erfantalab et al., 2017). Therefore, the aim of this study was to identify different predictive variables of acute AlP poisoning outcome. Then, propose and internally validate a simple outcome prediction model to be applied in the emergent clinical settings for cases of acute AlP poisoning.

\section{PATIENTS AND METHODS}

This prospective cohort study was carried out on patients with acute AlP poisoning admitted to Tanta Poison Control Center, Tanta University, Egypt in the period from January, 2018 to December, 2018. These patients were included as derivation group. Then, patients admitted during the period from January, 2019 to June, 2019 were included as validation group.

The protocol of the study was approved by the institution research ethical committee. A written informed consent was obtained from each participant or his/her guardian if the patient was unfit to give consent. Confidentiality of the data was maintained by making code number for every patient.

Diagnosis of acute AlP poisoning was based on history of exposure, identification of the agent by containers brought by the patients' attendants, clinical manifestations suggesting acute AlP poisoning and silver nitrate test to detect phosphine gas in the gastric content. All patients aged 18 years or more admitted with acute AlP poisoning were included in the study. However, patients presented with mixed toxicological exposure, associated trauma and those with pre-existing chronic diseases or received any medical treatment before admission were excluded. 
Age, sex and toxicological characteristics were obtained from all patients and the duration of hospital stay was registered. Clinical examination including vital signs, conscious level using GCS and examination of cardiovascular, respiratory and gastrointestinal systems was performed. Routine laboratory investigations including arterial blood gases, serum electrolytes, random blood glucose level, renal functions, liver functions, complete blood count and coagulation profile were done and central venous pressure (CVP) was measured. A twelve- leads ECG was recorded and corrected QT interval (QTc) was measured according to Bazett's formula; QTc $=$ QT/vRR (normal value up to 440 milliseconds) (Bazett, 1920; Crotti et al., 2008).

All cases were treated according to Tanta Poison Control Center protocol based on respiratory and cardiovascular support, gastric lavage with sodium bicarbonate and correction of metabolic acidosis and electrolytes disturbance. Cases were divided according to their final outcome into survivors and non-survivors.

\section{Statistical analysis:}

Data were fed to the computer and analyzed using IBM SPSS software package version 20.0. (Armonk, NY: IBM Corp). The Kolmogorov-Smirnov test was used to verify the normality of distribution. Comparisons between groups for categorical variables were assessed using Chi-square test (Fisher or Monte Carlo). Mann Whitney test was used to compare two groups for abnormally distributed quantitative variables while Student t-test was used to compare two groups for normally distributed quantitative variables. Univariate and multivariate regression analysis were applied to detect variables affecting the outcome. Receiver operating characteristic
(ROC) analysis was used to determine the diagnostic performance of the variables and to calculate the sensitivity and specificity for the chosen cut off. Area under the curve (AUC) more than 50\% gives acceptable performance and area about $100 \%$ is the best performance for the test. Multiple logistic regressions were used to detect the most independent variables for mortality to construct the outcome prediction model. Significance of the obtained results was judged at the 5\% level. Then, ROC methodology was used to assess the discriminative power of the outcome prediction model in both the derivation and validation groups.

\section{RESULTS}

A total of 110 acute AlP poisoned patients met our inclusion criteria and were included into the study as the derivation group. Survivors were 46 cases (41.82\%), while non-survivors were 64 cases $(58.18 \%)$. Table (1) illustrated comparison between survivors and non-survivors regarding their age, sex, toxicological characteristics and clinical manifestations at admission. There was statistical difference between survivors and non-survivors regarding age, level of consciousness measured by GCS, presence of agitation, systolic \& diastolic blood pressure, respiratory rate, temperature, oxygen saturation and CVP.

Both of chest manifestations (diminished air entry, wheezes, crepitation and pulmonary edema) and cardiovascular manifestations (tachycardia, bradycardia, hypotension and shock) were significantly manifested in the non-survivors. No statistical difference was found between survivors and non-survivors regarding presence of gastrointestinal manifestations (vomiting, epigastric tenderness, abdominal pain) or detected ECG abnormalities (atrial 
fibrillation, depressed or elevated ST segment, inverted $\mathrm{T}$ wave, sinus bradycardia, ventricular tachycardia and 1st degree heart block). Non-survivors had significant prolonged QTc interval. The hospital stay was significantly longer in the survivors (Table 1).

Statistical analysis of routine laboratory investigations at admission was shown in table (2). It revealed significantly lower $\mathrm{pH}$, $\mathrm{HCO}_{3}, \mathrm{PaO}_{2}$, serum potassium level and prothrombin concentration in the nonsurvivors. While, random blood glucose, serum creatinine, total bilirubin, alanine aminotransferase, total white blood cells count, red cell distribution width, prothrombin \& partial thromboplastin time and international normalized ratio were significantly higher in the non-survivors.

\section{Construction of an outcome prediction model:}

Out of all studied variables, systolic blood pressure (SBP), CVP, $\mathrm{pH}$ and prothrombin time were the significant predictive variables after both univariate and multivariate regression analysis. Cut off value of each of these variables were detected from the ROC analysis to be used for construction of an outcome prediction model (Table 3).

To test the reliability of these four factors at their cut off values, univariate and multivariate regression analysis were repeated. Table (4) showed that these variables were significant when their cut-off values were used in univariate analysis, but prothrombin time was not included in the proposed model because it was not statistically significant when multivariate regression analysis was done.
Table (5) illustrated the proposed outcome prediction model. Each variable was given points according to its correlation with the outcome and the maximum sum points of the proposed model were ten. Using Mann Whitney test, non-survivors of derivation group had significantly higher median sum points of the model than survivors (U: 77.0, $p<0.001$ ).

The accuracy of this model to predict the outcome of acute AlP poisoned patients was assessed by the ROC analysis. The best cut off sum points were $\geq 4$ and $\geq 5$ meaning that if the patient had sum points of the prediction model $\geq 4$ or $\geq 5$, the patient had bad outcome and if it was $<4$ or $<5$, the patient had a good outcome (Table 6, Fig. 1).

\section{Validity of the proposed outcome prediction model:}

The proposed model was internally validated on a new set of 58 patients with acute AlP poisoning matching with the derivation group for their age, sex, toxicological data and laboratory investigations at admission ( $p$ value: > $0.05)$. It was tested by assessing its ability to predict the outcome of patients of the validation group at admission corresponding to their outcome at discharge. The nonsurvivors of validation group had significantly higher median sum points of the model than survivors when compared by Mann Whitney test (U: 65.50, $p<0.001)$.

The ROC analysis was performed to assess the accuracy of this model to predict the outcome of the validation group. The AUC for the prediction model was 0.917 when the best cut off value ( $\geq 4$ and $\geq 5$ sum points) was used (Table 7, Fig. 2). 
TABLE 1 Statistical analysis of derivation group regarding age, sex, toxicological data and clinical manifestations at admission

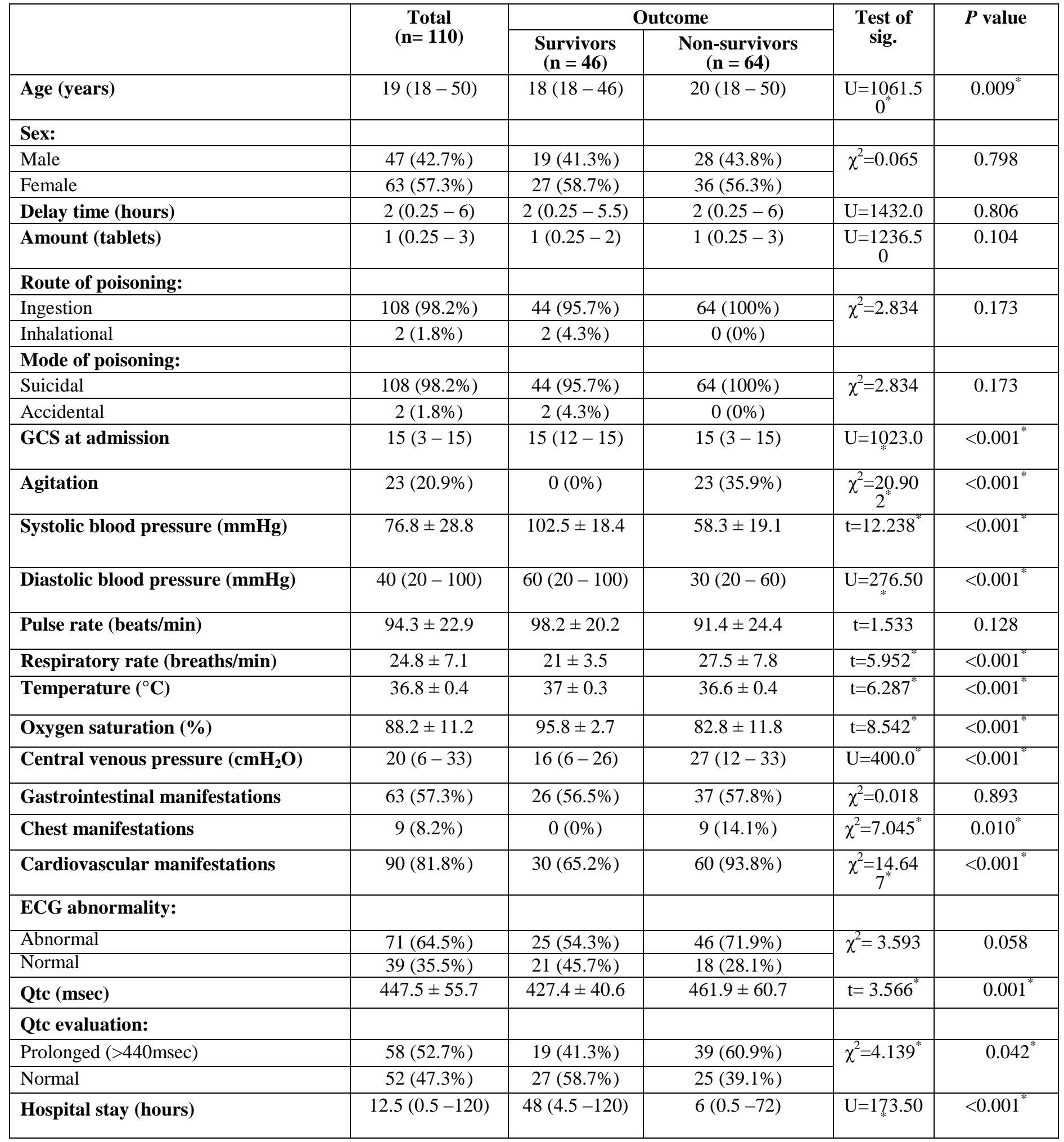

Values are presented as mean \pm standard deviation, number (\%), or median (min.-max.); *: Statistically significant at $p \leq 0.05 ; \chi^{2}$ : Chi square test; t: Student t-test; U: Mann Whitney test; GCS: Glasgow Coma Scale; ECG: Electrocardiogram; QTc: corrected QT interval 
TABLE 2 Statistical analysis of derivation group regarding laboratory investigations at admission

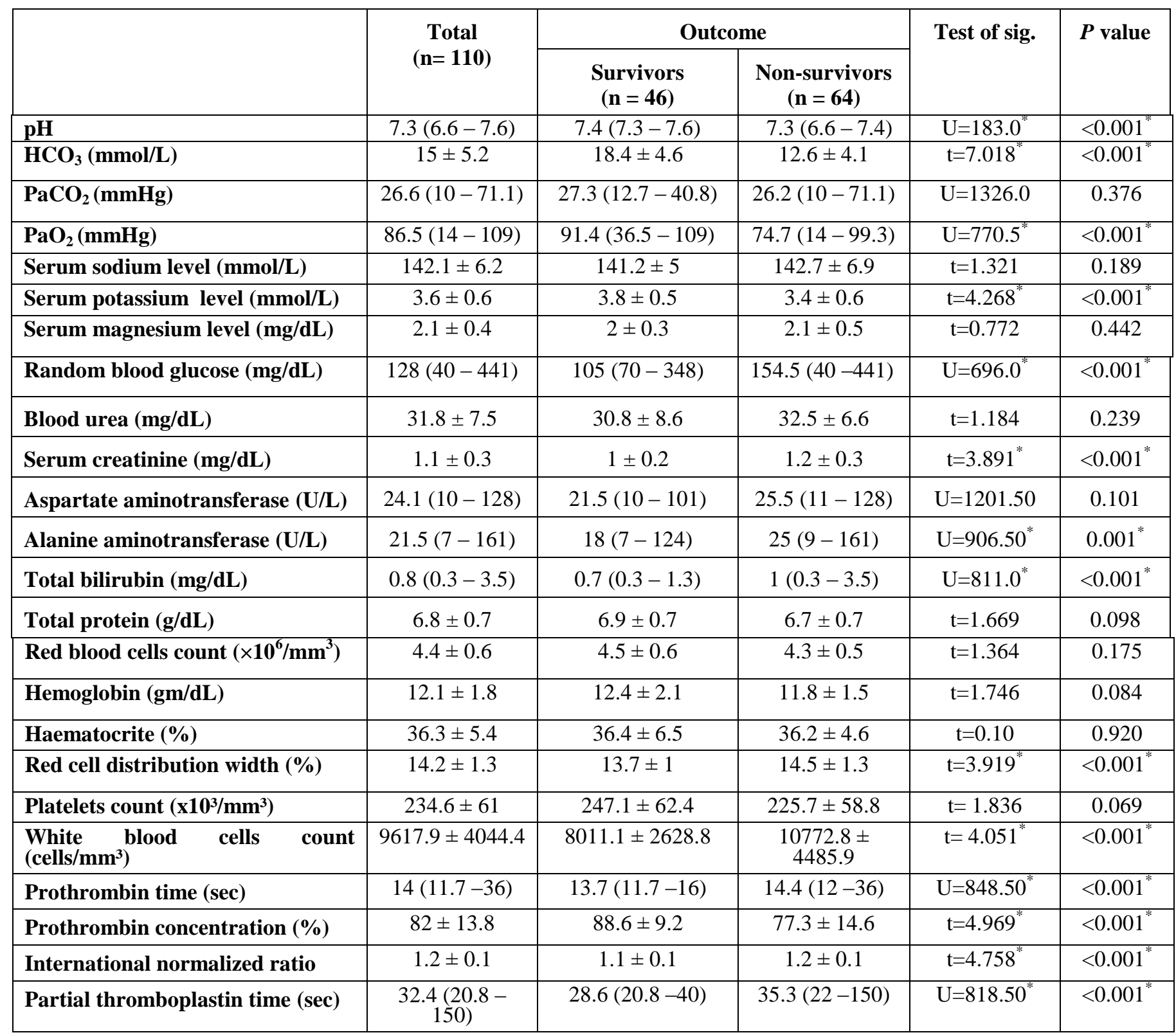

Values are presented as mean \pm standard deviation, number (\%), or median (min.-max.); *: Statistically significant at $p \leq 0.05 ; \chi^{2}$ : Chi square test; t: Student t-test; U: Mann Whitney test 
TABLE 3 Agreement (sensitivity, specificity) for the significant predictive variables in the derivation group to predict mortality

\begin{tabular}{|l|c|c|c|c|c|c|c|c|}
\hline & AUC & $P$ value & $\mathbf{9 5 \%}$ C.I & Cut off & $\begin{array}{c}\text { Sensitivi } \\
\text { ty }\end{array}$ & $\begin{array}{c}\text { Specifici } \\
\text { ty }\end{array}$ & PPV & NPV \\
\hline SBP $(\mathbf{m m H g})$ & 0.960 & $<0.001^{*}$ & $0.90-0.99$ & $\leq 85$ & 90.62 & 89.13 & 92.1 & 87.2 \\
\hline CVP $\left(\mathbf{c m H}_{\mathbf{2}} \mathbf{O}\right)$ & 0.864 & $<0.001^{*}$ & $0.77-0.92$ & $>22$ & 67.19 & 93.48 & 93.5 & 67.2 \\
\hline pH & 0.938 & $<0.001^{*}$ & $0.88-0.98$ & $\leq 7.33$ & 76.69 & 93.48 & 94.4 & 76.8 \\
\hline $\begin{array}{l}\text { Prothrombin time } \\
\text { (sec) }\end{array}$ & 0.712 & $<0.001^{*}$ & $0.62-0.79$ & $>14.6$ & 46.88 & 86.96 & 83.3 & 54.1 \\
\hline
\end{tabular}

AUC: Area under the curve;*: Statistically significant at $p \leq 0.05$; CI: Confidence interval; PPV: Positive predictive value; NPV: Negative predictive value; SBP: Systolic blood pressure; CVP: Central venous pressure

TABLE 4 Univariate and multivariate analysis for the significant predictive variables affecting mortality in the derivation group

\begin{tabular}{|c|c|c|c|c|c|}
\hline & \multicolumn{2}{|r|}{ Univariate } & \multicolumn{3}{|c|}{${ }^{\#}$ Multivariate } \\
\hline & $P$ value & OR $(95 \%$ C.I $)$ & B & $P$ value & OR $(95 \%$ C.I $)$ \\
\hline Systolic blood pressure ( $\leq 85 \mathrm{mmHg}$ ) & $<0.001^{*}$ & $79.267(22.656-277.328)$ & 3.528 & $<0.001^{*}$ & $34.053(5.844-197.064)$ \\
\hline Central venous pressure $\left(>22 \mathrm{cmH}_{2} \mathrm{O}\right)$ & $<0.001^{*}$ & $29.349(8.148-105.711)$ & 2.708 & $0.011^{*}$ & $15.005(1.885-119.467)$ \\
\hline pH $(\leq 7.33)$ & $<0.001^{*}$ & $56.231(15.031-210.355)$ & 3.301 & $0.001^{*}$ & $27.137(3.758-195.958)$ \\
\hline Prothrombin time (>14.6 sec.) & $<0.001^{*}$ & $5.882(2.189-15.809)$ & 0.967 & 0.316 & $2.630(0.398-17.392)$ \\
\hline
\end{tabular}

*: Statistically significant at $p \leq 0.05$; OR: Odd`s ratio; CI: Confidence interval

TABLE 5 The proposed outcome prediction model

\begin{tabular}{|l|c|c|c|c|c|c|c|}
\hline Variables & \multicolumn{2}{|c|}{ Systolic blood pressure } & \multicolumn{2}{|c|}{ Central venous pressure } & \multicolumn{2}{|c|}{ PH } & \\
\hline Findings & $\leq 85 \mathrm{mmHg}$ & $>85 \mathrm{mmHg}$ & $>22 \mathrm{cmH}_{2} \mathrm{O}$ & $\leq 22 \mathrm{cmH}_{2} \mathrm{O}$ & $\leq 7.33$ & $>7.33$ & \\
\hline Points & 4 & 0 & 3 & 0 & 3 & 0 & $\begin{array}{c}\text { Maximum sum } \\
\text { points=10 }\end{array}$ \\
\hline
\end{tabular}

TABLE 6 Agreement (sensitivity, specificity) for the outcome prediction model in the derivation group

\begin{tabular}{|c|c|c|c|c|c|c|c|c|}
\hline & AUC & $\boldsymbol{P}$ & $\mathbf{9 5 \%}$ C.I & Cut off & $\begin{array}{c}\text { Sensitivi } \\
\text { ty }\end{array}$ & $\begin{array}{c}\text { Specifici } \\
\text { ty }\end{array}$ & PPV & NPV \\
\hline $\begin{array}{c}\text { Sum points } \\
\text { of the } \\
\text { proposed } \\
\text { model }\end{array}$ & 0.974 & $<0.001^{*}$ & $0.947-1.0$ & $\geq \mathbf{4}$ & 93.75 & 89.13 & 92.3 & 91.1 \\
\cline { 3 - 7 } & & & $\mathbf{2 5}$ & 85.94 & 97.83 & 98.2 & 83.3 \\
\hline
\end{tabular}

AUC: Area under the curve; $*$ : Statistically significant at $p \leq 0.05$; CI: Confidence interval; PPV: Positive predictive value; NPV: Negative predictive value 
TABLE 7 Agreement (sensitivity, specificity) for the proposed outcome prediction model after application on the validation group

\begin{tabular}{|l|c|c|c|c|c|c|c|}
\hline \multirow{2}{*}{$\begin{array}{c}\text { Sum points of } \\
\text { the proposed } \\
\text { model }\end{array}$} & \multicolumn{2}{|c|}{ Outcome } & Sensitivity & Specificity & PPV & NPV & Accuracy \\
\cline { 2 - 4 } & $\begin{array}{c}\text { Survivors } \\
(\mathbf{n}=\mathbf{2 2})\end{array}$ & $\begin{array}{c}\text { Non-survivors } \\
(\mathbf{n = 3 6})\end{array}$ & & & & & \\
\hline$<4$ & $16(72.7 \%)$ & $3(8.3 \%)$ & 91.67 & 72.73 & 84.62 & 84.21 & 84.48 \\
\hline$\geq \mathbf{4}$ & $6(27.3 \%)$ & $33(91.7 \%)$ & & & & \\
\hline$<\mathbf{5}$ & $19(86.4 \%)$ & $4(11.1 \%)$ & 88.89 & 86.36 & 91.43 & 82.61 & 89.93 \\
\hline$\geq \mathbf{5}$ & $3(13.6 \%)$ & $32(88.9 \%)$ & & & & & \\
\hline
\end{tabular}

PPV: Positive predictive value; NPV: Negative predictive value

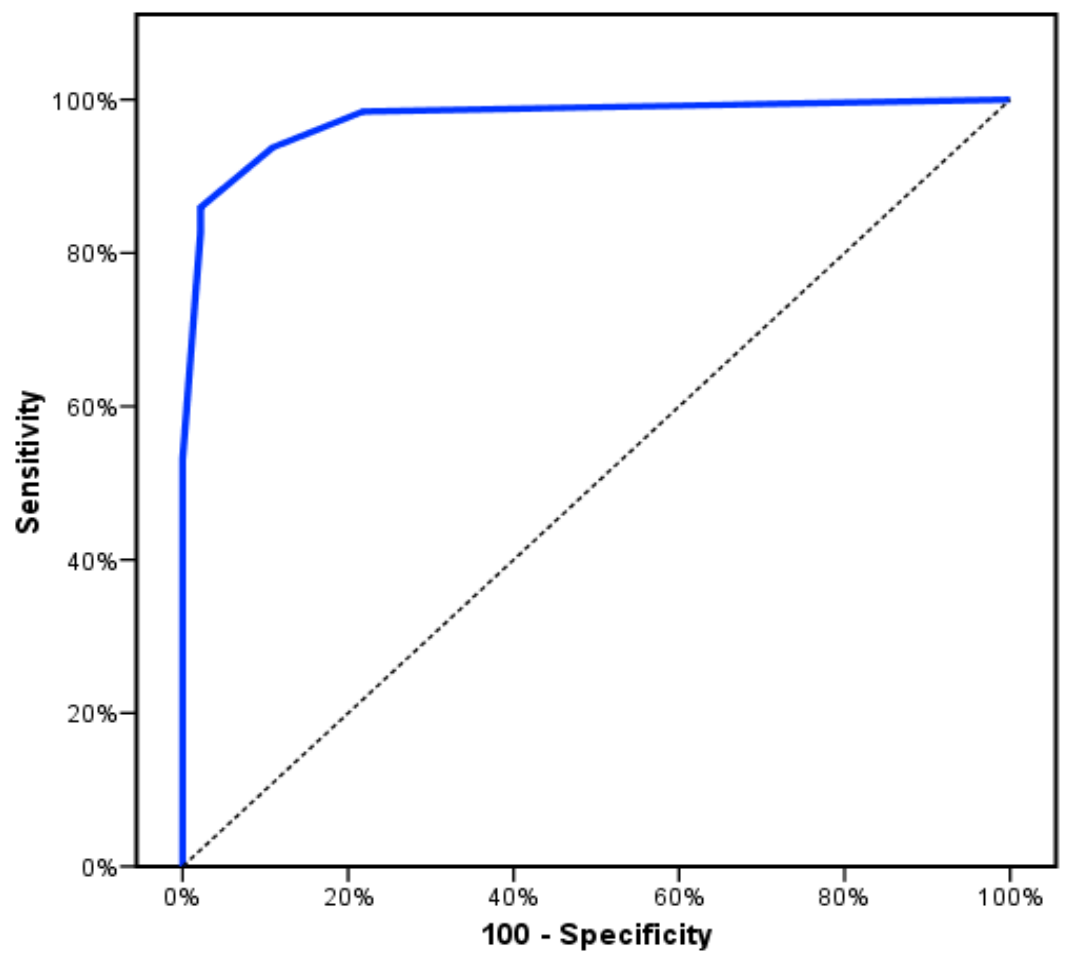

FIGURE 1: ROC curve for sum points of the outcome prediction model in the derivation group 


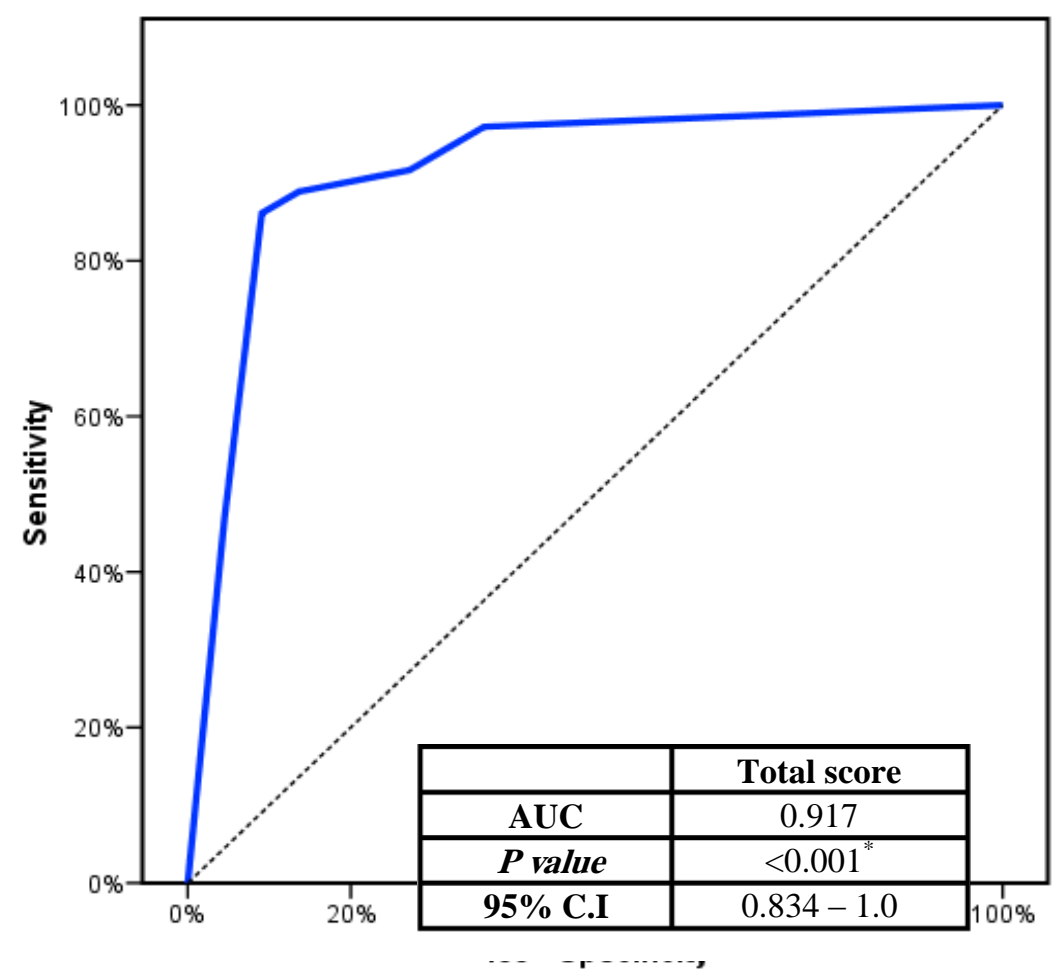

FIGURE 2: ROC curve for the proposed outcome prediction model after application on validation group

AUC: Area under a curve; *: Statistically significant at $\mathrm{p} \leq 0.05$; CI: Confidence interval

\section{DISCUSSION}

Aluminum phosphide is a widely available pesticide that is frequently encountered in suicidal and accidental poisoning (Rahimin et al., 2018). The mortality rate of derivation group in this study was 58.2\%; generally, the overall mortality rate of acute AlP poisoning may reach up to $77 \%$ (Hena et al., 2018). Age, sex and toxicological characteristics of patients in the current study were more or less comparable to data obtained from other studies in different toxicological centers in Egypt and worldwide (Masoud and Barghash, 2013; Hassanian-Moghaddam and Zamani, 2016; Halvaei et al., 2017; Hegazy et al., 2019).

Manifestations of acute AlP poisoning occur rapidly after liberation of phosphine gas and death may ensue within 24 to 48 hours (Navabi et al., 2018). Organs with high oxygen requirements (brain, heart, liver and kidneys) are more susceptible to damage resulting from cytochrome oxidase inhibition and hypoxia (Masoud and Barghash, 2013).

In the current study, statistical difference was found between survivors and non-survivors regarding GCS and occurrence of agitation; this was in agreement with Sulaj et al. (2015) and ElSarnagawy (2017). On the other hand, Erfantalab et al. (2017) found that, GCS did not significantly affect the outcome. Patients may suffer headache, giddiness, convulsion and coma; meanwhile consciousness may be maintained till late stages depending on degree of hypotension and hypoxia (Lourizet al., 2009; Gurjar et al., 2011).

Regarding vital signs, both systolic and diastolic blood pressure were significantly 
lower in non-survivors compared to survivors in this study. Shock in acute AlP poisoning is multifactorial; myocardial damage and fluid loss together with adrenal gland damage seem to be the main contributing factors (Proudfoot, 2009). In the same line, CVP was significantly higher in non-survivors; this finding was in accordance with Ghazi (2013) and Bansal et al. (2017) who stated that, elevated jugular venous pressure is one of the cardiovascular effects of acute AlP poisoning. Meanwhile, pulse rate was not found as a significant factor that could influence the outcome; this was in accordance with El-Sarnagawy (2017). On the other hand, Sharma et al. (2018) registered that pulse rate was significantly higher in non-survivors compared to survivors.

In this regard, abnormal ECG findings were observed in $64.5 \%$ of the studied cases. According to El-Ebiary et al. (2015), acute AlP poisoning could induce ECG changes due to depletion of myocardial energy that alters cardiac trans-membrane action potential due to toxic effect of phosphine gas. Moreover, prolonged QTc interval was observed in $52.7 \%$ of the studied patients; this was in line with Soltaninejad et al. (2012). Prolonged QTc interval indicates impending ventricular arrhythmias (Roden, 2008).

This study revealed that, respiratory rate was significantly increased and oxygen saturation was significantly decreased in non-survivors. Additionally, chest manifestations were significantly manifested in the non-survivors. According to Demir et al. (2017), respiratory system is commonly affected in acute AIP poisoning resulting in tachypnea, dyspnea and development of rhonchi, crepitation and pulmonary edema. Phosphine gas reacts with lung moisture producing phosphoric acid that causes alveolar membrane damage (Anand et al., 2011). In the current study, temperature was significantly lower in non-survivors; this may be attributed to vomiting and shock state. For arterial blood gases, non-survivors had significantly lower $\mathrm{pH}$ and serum bicarbonate than survivors; this was in accordance with Farzaneh et al. (2018). Metabolic acidosis could be attributed to lactic acid accumulation due to oxidative phosphorylation inhibition and poor tissue perfusion (Gurjar et al., 2011).

In the current study, random blood glucose level was significantly higher in non-survivors. Mehrpour et al. (2008) suggested hyperglycemia as a marker of severity in acute AlP poisoning. Hyperglycemia could be attributed to pancreatic $\beta$-cells damage by lipid peroxidation or the potential associated acute pancreatitis that results from extensive cytokine release, acidosis and/or ischemia (Verma et al., 2007). However, severe hypoglycemia has also been reported due to adrenal damage and decreased cortisol level (Proudfoot, 2009). Serum potassium level was significantly lower in non-survivors while other electrolytes had no statistical difference. Hashemi-Domeneh et al. (2016) attributed hypokalaemia in acute AlP poisoning to vomiting or catecholamine release. Even so, serum electrolytes findings in acute AlP poisoning are controversial (Louriz et al., 2009; Shadnia et al., 2010; El-Sarnagawy 2017).

Serum creatinine was significantly higher in non-survivors of the studied patients. Serum creatinine level more than $1.0 \mathrm{mg} / \mathrm{dL}$ was associated with increased risk of mortality and considered a poor prognostic factor in acute AlP poisoning (Bansal et al., 2017; Sharma et al., 2018). Renal function impairment in acute AlP poisoning is due to hypoxia and shock (Masoud and Barghash, 2013). In the 
current study, alanine aminotransferase and total bilirubin were significantly higher in non-survivors. Liver is affected in acute AlP poisoning due to tissue hypoperfusion or direct toxic effect of phosphine gas (Soltaninejad et al., 2011). According to Memis et al. (2007), elevated hepatic enzymes were observed in fatal cases. Additionally, jaundice may occur as a result of hepatic damage or intravascular haemolysis (Mehrpour et al., 2012).

For hematological variables, total white blood cells count and red cell distribution width were significantly higher in nonsurvivors. Previous studies found that, leukocytosis was a prognostic marker that could predict the mortality and it may be physiological response to stress, hypoxia or toxin exposure (Louriz et al., 2009; Masoud and Barghash, 2013). According to Surana and Sharma (2016), increased red cell distribution width was associated with high mortality index as acute AlP poisoning causes morphological changes of erythrocytes elevating red cell distribution width. Furthermore, there was statistical difference between survivors and nonsurvivors regarding prothrombin time, prothrombin concentration, international normalized ratio and partial thromboplastin time. This disturbance of coagulation profile could be explained by that disseminated intravascular coagulation is a probable complication in acute AlP poisoning (Anand et al., 2011; Mahajan and Parga, 2012).

Univariate and multivariate regression analysis detected that, the significant variables of acute AlP outcome in the present study were SBP, CVP, $\mathrm{pH}$ and prothrombin time. This was in accordance with previous studies that identified the predictive variables in acute AlP poisoned patients (Wahab, et al., 2008; Taghadosinejad et al., 2014). According to
Navabi et al. (2018), each of blood pressure, blood $\mathrm{pH}$, and pre-hospitalization period were the most significant determinants for acute AlP poisoning outcome using multivariate logistic regression. Moreover, Rahbar Taramsary et al. (2006) demonstrated a mortality rate $92.1 \%$ at SBP below $90 \mathrm{mmHg}$.

The current study generated a simple outcome prediction model for acute AlP poisoning which combined three measurable variables (SBP, CVP and $\mathrm{pH}$ at cut off $\leq 85$ $\mathrm{mmHg}, \quad>22 \quad \mathrm{cmH} 2 \mathrm{O}$ and $\leq 7.33$ respectively). Refractory cardiogenic shock and cardiac dysrhythmia together with severe hypotension and metabolic acidosis are considered the main mechanism of death in acute AlP poisoning that could support the incorporation of the previous factors in the proposed model (Nejad et al., 2012; Taghaddosinejad et al., 2016).

The performance of the proposed model at cut off value $\geq 4$ or $\geq 5$ was excellent (AUC: 0.974 ). Using cut off value $\geq 4$, the sensitivity of the model was 93.75 meaning low number of false positives together with positive predictive value 92.3 that indicated the probability of a patient with cut off value $\geq 4$ to die was $92.3 \%$. Additionally, negative predictive value 91.1 indicated that the probability of a patient with cut off $<4$ to survive was $91.1 \%$. Furthermore, using a cut off value $\geq 5$, the sensitivity of the model was 85.94, positive predictive value was 98.2 and negative predictive value was 83.3. High positive and negative predictive values reflect the usefulness of the proposed model.

The discriminatory power of the model in the validation group was excellent (AUC: 0.917) with high positive and negative predictive values when the best cut off $\geq 4$ and $\geq 5$ sum points of the proposed model were used. This means that this proposed model can be used as a simple method to 
predict the outcome of acute AlP poisoned patients in the emergency room.

\section{CONCLUSION AND RECOMMENDATIONS}

From data of the current study, it could be concluded that, SBP, CVP, $\mathrm{pH}$ and prothrombin time were significant predictors for acute AlP poisoning outcome. This proposed model could provide excellent survival-mortality discrimination power for cases of acute AlP poisoning. Other studies are recommended for external validation and evaluation of the proposed model.

\section{REFERENCES}

Anand, R.; Binukumar, B.K. and Gill, K.D. (2011): Aluminum phosphide poisoning: an unsolved riddle. J. App. Toxicol., 31:499-505.

Bansal, P.; Giri, S.; Bansal, R. and Tomar, L.R. (2017): Survival in a case of aluminum phosphide poisoning with severe myocardial toxicity. Indian $\mathrm{J}$. Health Sci. Biomed. Res., 10:343-346.

Bazett, H.C. (1920): An analysis of time relations of the electrocardiogram. Heart, 7:353-370.

Crotti, L.; Celano, G.; Dagradi, F. and Schwartz, P.J. (2008): Congenital long QT syndrome. Orphanet. J. Rare Dis., $3: 18$.

Demir, U.; Hekimoglu, Y.; Asirdizer, M.; Etli, Y.; Kartal, E. and Gumus, O. (2017): A case who died due to the suicidal intake of aluminum phosphide. Cumhuriyet. Medical Journal, 39:458465.

El-Ebiary, A.A.; Elgazzar, F.M.; Soliman, M.A. and Shouip, O.M. (2015): Predictors of prognosis in acute aluminum phosphide poisoning.
Mansoura J. Forensic Med. Clin. Toxicol., 23:13-27.

El-Sarnagawy， G.N. (2017): Predictive factors of mortality in acute aluminum phosphide poisoning: 5 Years retrospective study in Tanta Poison Control Unit. Ain Shams J. Forensic Med. Clin. Toxicol., 29:70-79.

Erfantalab, P.; Soltaninejad, K.; Shadnia, S.; Zamani, N.; HassanianMoghaddam, H.; Mahdavinejad, A.; et al. (2017): Trend of blood lactate level in acute aluminum phosphide poisoning. World J. Emerg. Med., $8: 116-120$.

Farzaneh, E.; Ghobadi, H.; Akbarifard, M.; Nakhaee, S.; Amirabadizadeh, A.; Akhavanakbari, G. et al. (2018): Prognostic factors in acute aluminium phosphide poisoning: A risk-prediction nomogram approach. Basic Clin. Pharmacol. Toxicol., 123:347-355.

Ghazi, M.A. (2013): "Wheat pill (aluminum phosphide) poisoning"; Commonly ignored dilemma. A comprehensive clinical review. Professional Med. J., 20:855-863.

Goel, A. and Aggarwal, P. (2007): Pesticide poisoning. Natl. med. J. India., 20(4), 182-191.

Gurjar, M.; Baronia, A.K.; Azim, A. and Sharma, K. (2011): Managing aluminum phosphide poisonings. J. Emerg. Trauma Shock, 4:378-384.

Halvaei, Z.; Tehrani, H.; Soltaninejad, K.; Abdollahi, M. and Shadnia, S. (2017): Vitamin $\mathrm{E}$ as a novel therapy in the treatment of acute aluminum phosphide poisoning. Turk. J. Med. Sci., 47:795-800.

Hashemi-Domeneh, B.; Zamani, N.; Hassanian-Moghaddam, H.; Rahimi, M.; Shadnia, S. and Erfantalab, P. et 
al. (2016): A review of aluminium phosphide poisoning and a flowchart to treat it. Arh. Hig. Rada. Toksikol., 67:183-193.

Hassanian-Moghaddam, H. and Zamani, N. (2016): Therapeutic role of hyperinsulinemia/euglycemia in aluminum phosphide poisoning. Medicine (Baltimore), 95:e4349.

Hegazy, M.M.; Elagamy, S.E. and Salem, E.A. (2019): Pattern and predictors of death from aluminum and zinc phosphide poisoning: a two years prospective study. Egypt J. Forensic Sci. Appli. Toxicol., 19:73-85.

Hena, Z.; McCabe, M.E.; Perez, M.M. Sharma, M.; Sutton, N.J.; Peek, G.J.; et al. (2018): Aluminum phosphide poisoning: Successful recovery of multiorgan failure in a pediatric patient. Int. J. Pediatr. Adolesc. Med., 5:155158.

Louriz, M.; Dendane, T.; Abidi, K.; Madani. N.; Abouqal, R. and Zeggwagh, A.A. (2009): Prognostic factors of acute aluminum phosphide poisoning. Indian J. Med. Sci., 63:227234.

Mahajan, V. and Parga, I. (2012): Aluminum phosphide poisoning: An agent of sure death. Indian J. Forensic Med. Toxicol., 6:231-235.

Mashayekhian, M.; HassanianMoghaddam, H.; Rahimi, M.; Zamani, N.; Aghabiklooei, A. and Shadnia, S. (2016): Elevated carboxyhaemoglobin concentratios by pulse CO-Oximetry is associated with severe aluminum phosphide poisoning. Basic Clin. Pharmacol. Toxicol., 119:322-329.

Masoud, R.A. and Barghash, S.S. (2013): Laboratory prognostic potential for acute aluminum phosphide poisoning. Al-Azhar Assiut Med. J., 11:213-238.

Mehrpour, O.; Alfred, S.; Shadnia, S.; Soltaninejad, K.; Chalaki, N. and Sedaghat, M. (2008): Hyperglycemia in acute aluminum phosphide poisoning as a potential prognostic factor. Hum. Exp. Toxicol., 27:591-595.

Mehrpour, O.; Jafarzadeh, M. and Abdollahi, M. (2012): A systematic review of aluminum phosphide poisoning. Arh. Hig. Rada. Toksikol., 63:61-73.

Memis, D.; Tokatlioglu, D.; Koyuncu, O. and Hekimoglu, S. (2007): Fatal aluminium phosphide poisoning. Eur J. Anaesthesiol., 24:292- 293.

Navabi, S.M.; Navabi, J.; Aghaei, A.; Shaahmadi, $Z$. and Heydari, R. (2018): Mortality from aluminum phosphide poisoning in Kermanshah Province, Iran: characteristics and predictive factors. Epidemiol. Health, 40:e2018022.

Nejad, F.T.; Mohammadi, A.B.; Behnoush, B.; Kazemifar, A.M.; Nahandi, M.Z.; Dabiran, S. et al. (2012): Predictors of poor prognosis in aluminium phosphide intoxication. Iran J. Toxicol., 6:610-614.

Proudfoot, A.T. (2009): Aluminum and zinc phosphide poisoning. Clin. Toxicol. (Phila), 47:89-100.

Rahbar Taramsary, M.; Orangpoor, R. and Zarkami, $T$ (2006): Survey patients poisoned with aluminum phosphide (rice tablet). J. Guilan Univ. Med. Sci., 14:42-47.

Rahimin, N.; Abdolghaffari, A.H.; Partoazar, A.; Javadian, N.; Dehpour, T.; Mani, A.R.; et al. (2018): Fresh red blood cells transfusion protects against aluminum 
phosphide-induced metabolic acidosis and mortality in rats. PLoS One, 13:e0193991.

Roden, D.M. (2008): Keep the QT interval: it is a reliable predictor of ventricular arrhythmias. Heart Rhythm, 5:12131215.

Sagah, G.A.; Oreby, M.M.; El-Gharbawy, R.M. and Fathy, A.S. (2015): Evaluation of potential oxidative stress in Egyptian patients with acute zinc phosphide poisoning and the role of vitamin C. Int. J. Health Sci. (Qassim), 9:375-385.

Shadnia, S.; Mehrpour, O. and Soltaninejad, K. (2010): A simplified acute physiology score in the prediction of acute aluminum phosphide poisoning outcome. Indian J. Med. Sci., 64:532539.

Sharma, T.; Sharma, A. and Kapoor, D. (2018): Profile of aluminum phosphide poisoning in a tertiary care institute in the sub-Himalayan region. J. Family Med. Prim. Care, 7:581-393.

Soltani, M.; Shetab-Boushehri, S.F. and Shetab-Boushehri, S.V. (2016): Chemical reaction between boric acid and phosphine indicates boric acid as an antidote for aluminum phosphide poisoning. Sultan Qaboos Univ. Med. J., 16:e303-e309.

Soltaninejad, K.; Beyranvand, M.; Momenzadeh, S. and Shadnia, S. (2012): Electrocardiographic findings and cardiac manifestations in acute aluminum phosphide poisoning. J. Forensic Leg. Med., 19:291-293.

Soltaninejad, K.; Nelson, L.S.; Khodakarim, N.; Dadvar, Z. and Shadnia, S. (2011): Unusual complication of aluminum phosphide poisoning: Development of hemolysis and methemoglobinemia and its successful treatment. Indian J. Crit. Care Med., 15:117-119.

Sulaj, Z.; Drishti, A.; Çeko, I.; Gashi, A. and Vyshka, G. (2015): Fatal aluminum phosphide poisonings in Tirana (Albania), 2009 - 2013. DARU J. Pharm. Sci., 25:23-28.

Surana, A. and Sharma, S. (2016): Raised red cell distribution width as a prognostic tool for acute aluminium phosphide poisoning (AALPP) patients. J. Med. Sci. Clin. res., 4:13039-42.

Taghaddosinejad, F.; Farzaneh, E.; Ghazanfari-Nasrabad, M.; EizadiMood, N.; Hajihosseini, M. and Mehrpour, O. (2016): The effect of Nacetyl cysteine (NAC) on aluminum phosphide poisoning inducing cardiovascular toxicity: a case-control study. Springerplus, 5:1948.

Taghadosinejad, F.; Behnoush, B.; Okazi, A.; Marashi, S.M.; Mohseni, K. and Sadeghian, M. (2014): A study of poisoning induced shock in patients referred to Baharloo Hospital from June 2011 to June 2012. Razi J. Med. Sci., 21:49-59.

Verma, S.K.; Ahmad, S.; Shirazi, N.; Barthwal, S.P.; Khurana, D.; Chugh, M. and Gambhir, H.S. (2007): Acute pancreatitis: a lesser-known complication of aluminum phosphide poisoning. Hum. Exp. Toxicol., 26: 979-981.

Wahab, A.; Zaheer, M.S.; Wahab, S. and Khan, R.A. (2008): Acute aluminium phosphide poisoning: an update. Hong Kong J. Emerg. Med., 15:152-155.

Yan, H.; Xiang, P.; Zhang, S.; Shen, B. and Shen, M. (2017): Diagnosis of aluminum phosphide poisoning using a new analytical approach: forensic 
application to a lethal intoxication. Int.

J. Legal Med., 131:1001-1007. 


\section{الملخص العربي}

\section{المتغيرات التنبوية لنتائج التسمم الحاد بفوسفيد الألومنيوم: نموذج مقترح جديد}

$$
\begin{aligned}
& \text { د. منى محمد غنيم، *د. سارة ابراهيم الشرقاوى، د. هبه ابراهيم لاشين }
\end{aligned}
$$

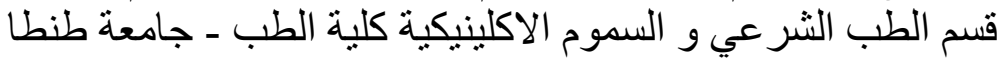

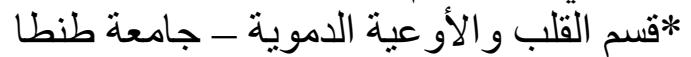

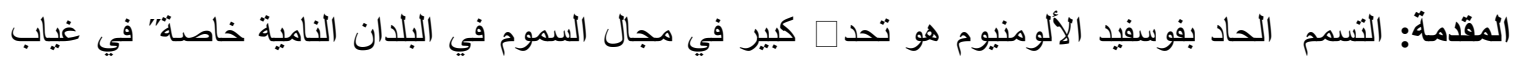

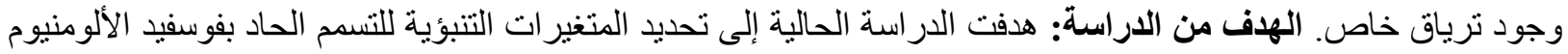

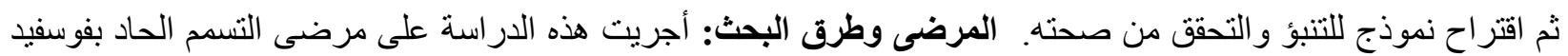

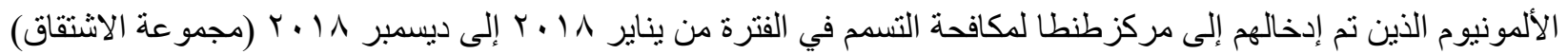

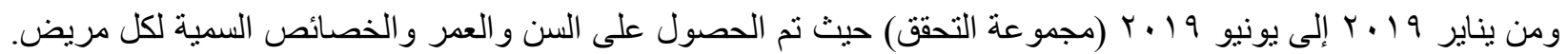
وكذلك تم إجر اء الفحص الإكلينيكى و الفحوصات المخبرية الروتينية وقياس الضغط الفئ الوريدي المركزي و التخطبط الكهربائي

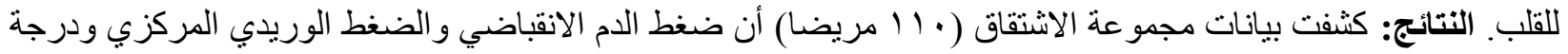

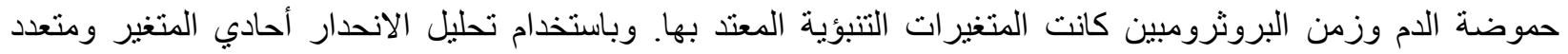

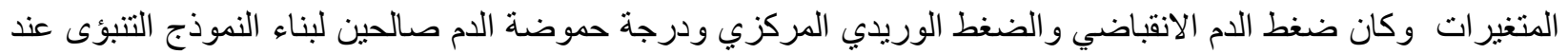

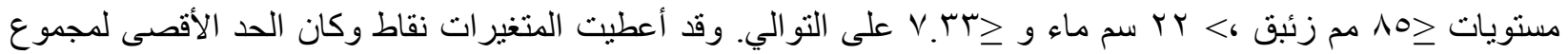

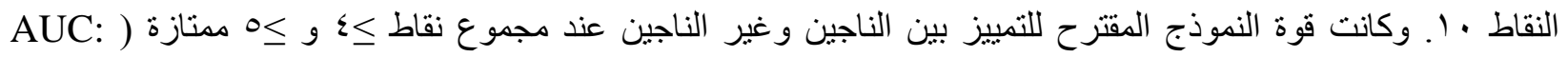

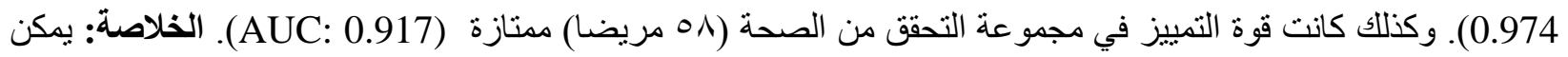

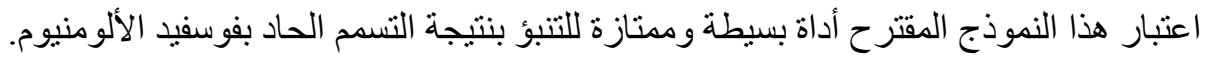
الكلمات المفتاحية: فوسفيد الألمونيوم ، التسمم ، النتائج ، الوفيات ، نموذج التنبؤ. 